\title{
Research on Relationships between Network Structure and Cluster Innovation Performance Based on SEM Simulation
}

\author{
ZHAO Peng1, a, LUO Fuzhou2, b \\ 1,2School of Management, Xi'an university of Architecture \& Technology, \\ Shaanxi Xi'an, 710055 \\ aemail:109297991@qq.com, bemail:foolish83@sina.com
}

\begin{abstract}
Network organizational structure lays a solid organizational innovation platform and provides a high-speed network channel for flow and diffusion of innovation cluster resources. First, the article discusses the mechanism of network organization structure characteristics and industrial cluster innovation performance through three dimensions of network node attributes. Second, the article builds a theoretical model taking network organization structure characteristics and cluster innovation performance as variables. Finally, the paper carries on the path fitting simulation and calculates the degree of fitting, and verifies the reasonable degree of theoretical model. The article further more explains the possible causes of path which is not pass the practice test.
\end{abstract}

Keywords: network structure; industrial cluster; factor analysis; path simulation; innovation performance

\section{Introduction}

It is worth thinking that why industrial cluster has strong vitality and become an important driving force of regional economic development. Academic world has given different explanations based on different research perspectives and all of these theoretical achievements have groundbreaking significance for us to discuss the source of industrial cluster innovation advantages. However, most of these documents study the external economic performance taking industrial cluster as a macroeconomic phenomenon while ignoring internal structure and interaction among nodes. With the development of industrial cluster network structure of this economic organization, structural analysis of internal network is particularly important for the research on innovation and competitiveness ${ }^{[1]}$. Changes of external environment makes cluster enterprises must transform innovation model from closed to open especially in the era of knowledge economy and flexible specialization. The location of innovation is turned from enterprise to cluster network ${ }^{[2]}$. Therefore, in the author's opinion, it is a beneficial attempt for us to research the relationships between industrial cluster 
network and cluster innovation performance by study network structure features in the view of theory blank in the field of organization analysis framework.

\section{Variable Selections and Model Building}

Network is the combination of points and lines. So we think cluster network structure is essentially the sum of position and relationship among network nodes ${ }^{[3]}$. So we call the research on nodes' relative position as structural dimension and nodes' relation as relational dimension. Structural dimension, which shows the explicit status of cluster network connection, mainly study relative position and quantity of nodes.

\subsection{Degree Centrality}

Degree centrality is used to describe the direct influence and measure the transaction ability of nodes in network ${ }^{[4]}$. We can use the following formula to calculate the degree centrality of a node if there are $\mathrm{N}$ nodes in the network:

$$
C_{d}(x)=d(x)
$$

$C_{d}(x)$ represents degree of $x$ and $d(x)$ represents the number of connection with the node. Degree centrality mainly shows the information capacity of the node, and the higher degree centrality, the greater the information capacity ${ }^{[5]}$.

\subsection{Closeness Centrality}

Closeness centrality reflects the degree of difficulty of a node reaching to other nodes through the network. Node $X$ 's closeness centrality can be defined

$$
\begin{aligned}
& p a_{i j}\left(k_{\text {min }}\right) \\
& : \\
C_{c}(x) & =\left[\sum_{y=1}^{N} p a_{x y}\left(k_{\text {min }}\right)\right]^{-1}
\end{aligned}
$$

Closeness centrality can be used to measure the closeness degree between one node and other nodes ${ }^{[6]}$. It is considered high closeness centrality if the distance is very short from the node to other nodes of network. High closeness centrality means that resources and information which can be absorbed are more and fast, which affects the transfer efficiency of innovation resources.

\subsection{Betweenness Centrality}

Betweenness centrality is used to express the number of a node appearing on the shortest path, which is the symbol for influence on information flow.

$$
C_{b}(x)=\sum_{j<k} g_{j k}(x) / g_{j k}
$$


$g_{j k}$ represents the number of the shortest path of $\mathrm{j}$ and $\mathrm{k}$. The node with high betweenness centrality is the dominant or core enterprise in cluster network. The node with high betweenness centrality has "structure hole" and "bridge" role. Betweenness centrality reflects the ability of node to control other related nodes ${ }^{[7]}$. As the information bridge, nodes in the structure hole position can decide whether to share and transmit useful information. Enterprise can get much more innovation resources if it can be the structure hole on more paths.

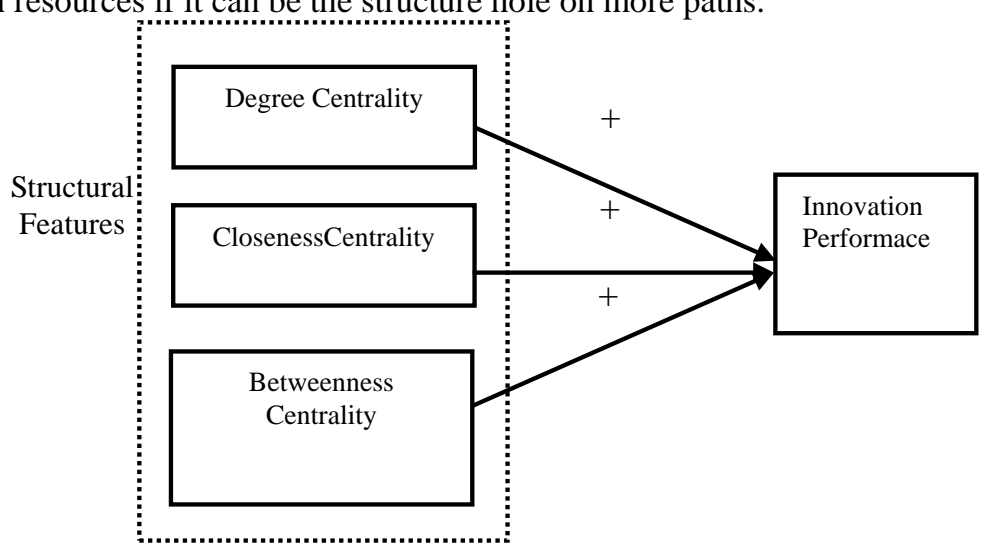

Fig. 1 Basic Theoretical Assumption

\section{Research Methods and Empirical Test}

\subsection{Data Analysis}

There are two reasons for us to select Baoji equipment manufacturing industrial cluster. First, as the western industrial city, Baoji is a typical industrial city with relatively strong industrial foundation. Second, most enterprises of Baoji equipment manufacturing industrial cluster focused on the Economic and technological development zone and industrial park, which is convenient for sample data collection.

\subsubsection{Reliability Analysis}

Whether a survey is carried out more than a single person or a single person repeated, the result should be roughly the same. We think that it has credibility ${ }^{[8] .}$ In this paper, Cronbach's Alpha coefficient is used to measure the internal consistency of measuring items. Cronbach's Alpha coefficients generally can be expressed as: WU Minglong thinks it is acceptable for reliability at least 0.7 in the exploratory research generally ${ }^{[9]}$.

$$
\alpha=\left(\frac{n}{n-1}\right)\left(1-\sum \frac{S_{i}^{2}}{S^{2}}\right)
$$


Table 1 Total Reliability Table

Reliability Statistics

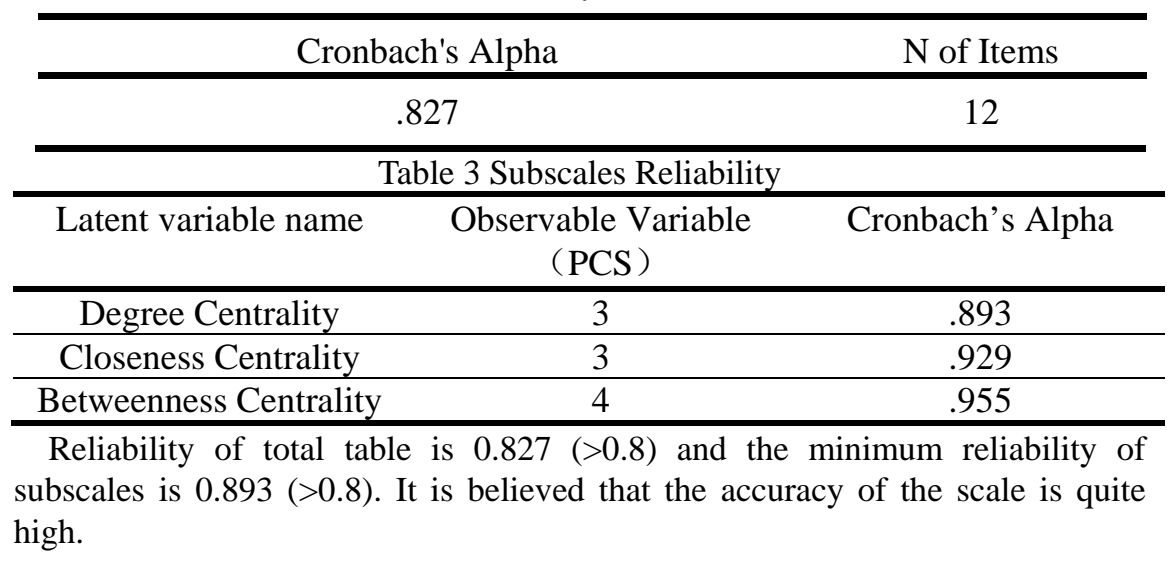

\subsubsection{Validity Analysis}

Validity Analysis refers to the degree of authenticity and accuracy of a study. This paper adopted confirmatory factor analysis to test validity.

Table 2 KMO and Bartlett sphere validity KMO and Bartlett's Test

\begin{tabular}{|c|c|c|}
\hline Kaiser-Meyer-Olki & ampling Adequacy. & .783 \\
\hline \multirow{3}{*}{ Bartlett's Test of Sphericity } & Approx. Chi-Square & 2435.640 \\
\hline & $\mathrm{df}$ & 66 \\
\hline & Sig. & .000 \\
\hline
\end{tabular}

It is generally believed that factor analysis will get better effect when KMO value above 0.7 . KMO value of this case is $0.783(>0.7)$, so we think it's very suitable for factor analysis. Each facet is formed different corresponding factors and factor loadings are greater than 0.6 . So structure validity passed by the test.

\subsection{Path Simulation}

According to 3 latent variables and 12 Observable Variables, we use Structural Equation Model (SEM) for data detection and path simulation. 


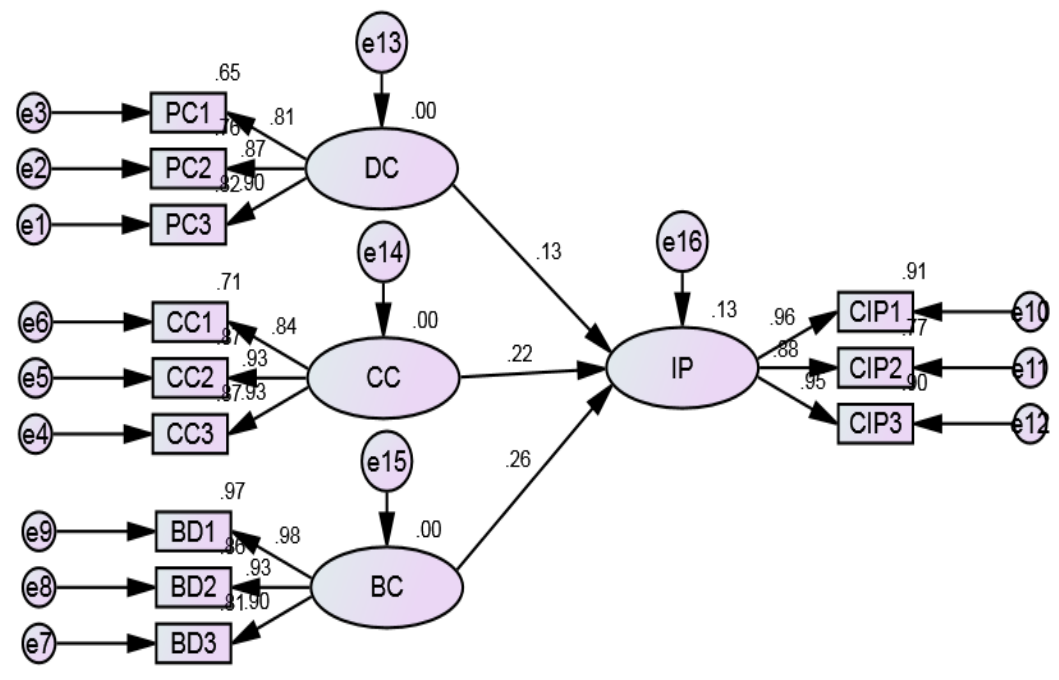

Fig.2 Path Simulation

Table 3 Model Fitting Path Coefficient

\begin{tabular}{|c|c|c|c|c|c|c|c|}
\hline & & & & & \multicolumn{2}{|c|}{ Estimate } & $\mathrm{P}$ \\
\hline $\begin{array}{c}\text { Innovation } \\
\text { Performance }\end{array}$ & $<---$ & \multicolumn{3}{|c|}{ Degree Centrality } & \multicolumn{2}{|c|}{.151} & 080 \\
\hline $\begin{array}{l}\text { Innovation } \\
\text { Performance }\end{array}$ & $<---$ & \multicolumn{3}{|c|}{ Closeness Centrality } & \multicolumn{2}{|c|}{.219} & 003 \\
\hline $\begin{array}{l}\text { Innovation } \\
\text { Performance }\end{array}$ & $<---$ & \multicolumn{3}{|c|}{ Betweenness Centrality } & \multicolumn{2}{|c|}{.235} & ${ }^{*}{ }^{*}$ \\
\hline \multicolumn{8}{|c|}{ Table 4 Model Fitting Standard and Index Scores } \\
\hline \multicolumn{2}{|c|}{ Index } & GFI & RMSEA & IFI & TLI & CFI & NFI \\
\hline \multirow{2}{*}{ Standard } & & $>0.7$ & \multirow{2}{*}{$<0.1$} & $>0.7$ & $>0.7$ & $>0.7$ & $>0.7$ \\
\hline & & $>0.9$ & & $>0.9$ & $>0.9$ & $>0.9$ & $>0.9$ \\
\hline \multicolumn{2}{|c|}{ Score } & 0.915 & 0.087 & 0.966 & 0.955 & 0.965 & 0.946 \\
\hline
\end{tabular}

If significance probability $\mathrm{P}$ value is less than 0.05 , we think the path is significant. P value of Innovation Performance <--- Degree Centrality is greater than 0.05 , so the effect could be insignificant as supposed.

\section{Conclusions}

Model fitting results show that the other two paths get the support except Innovation Performance <--- Degree Centrality. The possible reasons are: node with high degree centrality has "quantity" advantage of information, but the height of the "quality" and cannot be reflected. Too much redundant information can not upgrade cluster innovation performance on the contrary. Cluster innovation performance is a multidimensional concept which will be influenced 
by multiple factors. The compactness and centrality can effectively improve innovation performance and total variance explained rate can be as high as $87.736 \%$. The article breaks through study inertia of academic world to study the relationship and mechanism between network structure and cluster innovation performance through calculating structure characteristic variables using network structure analysis method in order to provide theoretical basis and policy guidance for cluster obtaining competitive advantages and sustainable development.

\section{References}

[1] TIAN Ying, HU Bei. Empirical study on the relationships between concentrating effect of industrial cluster and entrepreneurial intention[J]. Chinese Journal of management, 2014(7): 1029-1031.

[2] CAI Ning, YANG Shuanzhu, WU Jiebing. Industrial cluster risk study: A web-based perspective[J]. Chinese industrial economy, 2003(4): 59-64.

[3] LI Xueqian, ZHU Daoli, LI Jin, LIU Meiling. Network evolution of global production network perspective [J]. Science Technology Progress and Policy, 2010(7): 54-56.

[4] WU Aiqi. Enterprise cluster networked growth mechanism study[D], Zhejiang University, 2004, 63-65.

[ 5 ] Hansen, E.L. Entrepreneurial network strategies of small Chinese high-technology firms: a qualitative study[M]. JPROD INNOV MANAG, 2008, 25: 79-102.

[6] LI Zhigang. Research on the relationship between cluster network and enterprise innovation performance[J]. Studies in Science of Science, 2007, 25(4): 77-82.

[ 7 ]Wai-sum Siu\&Qiong Bao. Network strategies of small Chinese high-technology firms: a qualitative study[M]. JPROD INNOV MANAG, 2008, 25:79-102.

[8] LING Wenxuan, Fang Liluo. Psychological and behavioral measures[M]. China Machine PRESS, 2003: 111-113.

[9] WU Minglong. SPSS statistical applications of Practice [M]. Beijing: science press, 2003: 237-239. 